\title{
Cesarean section for women with dengue fever and thrombocytopenia complicated by post-partum psychosis: case report
}

\author{
Background \\ Post-partum psychosis (PPS) is a severe psychiatric condition affecting small \\ proportion of women shortly after child birth. The incidence of PPS is 1-2/ 1000 \\ child births. The pathophysiological mechanism and underlying risk for the condition \\ are poorly defined, but may include; altered immune function, altered tryptophan \\ metabolism and serotonergic dysfunction.1 This case report represents a case of \\ cesarean section for women with dengue fever and thrombocytopenia complicated \\ by post-partum psychosis to highlights the importance of multidisciplinary team \\ approach in management of such cases.
}

Volume 5 Issue I - 2019

\author{
Anuradha Tyagi \\ Santosh University, India
}

Correspondence: Anuradha Tyagi, Santosh University, 3rd E, 52 A, Nehru Nagar Ghaziabad, UP, India,

Emailanu_aquarian_86@yahoo.com

Received: January 17, 2019 | Published: February 12, 2019
Abbreviations: LSCS, lower segment cesaarean section; ICP, inter conceptional period; NS1, AG-non specific protein antigen detection test; PPS, post partum psychosis

\section{Case report}

A 34-years-old woman, un-booked case G3P1, pregnant 37 weeks gestation, presented to the gynecology triage of our hospital (Santosh medical college Ghaziabad) complaining of abdominal pain of 3 hours duration and one episode of fever. She had past obstetrics history of lower segment cesarean section (LSCS) done 14 months ago due to non-progress of Labor. Her current pregnancy achieved spontaneously, while she is nursing and lactating her bay on top of irregular cycles. On examination; she was afebrile (temperature $37.2^{\circ} \mathrm{C}$ ), pulse rate was 90 beats $/ \mathrm{min}$, blood pressure was $110 / 70 \mathrm{mmHg}$. She had no respiratory or cardio-vascular symptoms. Abdominal examination showed; fundal uterine level of full term pregnancy, with fetal heart rate of 134 beats/min, vertex presentation, $2 / 5$ of the fetal head felt abdominally and no previous cesarean section scar tenderness.

Vaginal examination showed; the uterine cervix was effaced with $2 \mathrm{~cm}$ dilated, pelvis was adequate, hence the studied woman was admitted as a case of previous LSCS early in labor under observation. On next day her baseline investigation showed; thrombocytopenia (platelet count $68.000 / \mathrm{mm}^{3}$ ) and attacks of persistent on and off fever which was managed with antipyretics and intravenous hydration.

The septic profile and cultures were completely negative and her fever was diagnosed by medical team (multidisciplinary team approach) as dengue fever with decreased platelet count (platelet counts $68.000 / \mathrm{mm}^{3}$ )

During the regular uterine contractions and progress of her labor process, the studied woman complained of tenderness over the previous cesarean section scar and delivered by repeat cesarean section due to suspected impending scar dehiscence because of the inter-conceptional period (ICP).

Intra-operatively; during the current cesarean section the previous cesarean section scar found dehiscent and she received 4 units' platelets (because of the lower pre-operative platelet count) and 1 unit of packed whole blood. Intra-peritoneal drain was inserted at the end of the cesarean section before closure of the anterior abdominal wall. The amount of blood collected in the intra-abdominal drain increased frequently in the first few post-operative hours, hence exploratory laparotomy done for the studied woman to secure any bleeders. During the exploratory laparotomy no definite bleeders were found and the case was managed by platelet transfusion to increase the postoperative platelets count (platelet count was $64000 / \mathrm{mm}^{3}$ after platelet transfusion).

After platelet transfusion; the blood collected in the intraabdominal drain decreased markedly in the subsequent post-operative days till the drain removed on the $4^{\text {th }}$ post-operative day. The studied woman shifted to the post-natal ward on $9^{\text {th }}$ post-operative day and in the post-natal ward she developed aggressive behavior against the medical staff and her new-born, refusing any medication, violence against family, shouting and running in wards. The studied woman diagnosed as post-partum psychosis by the psychiatric team (multidisciplinary team approach) managed by haloperidol injection followed by oral haloperidol, lorazepam and olanzapine. After few days her other antipsychotics were tapered gradually and she was discharged on haloperidol tablets only. According to family members she was comfortable at home on haloperidol tablets alone.

\section{Discussion}

Diagnosis of the studied case as post-partum psychosis was based on her psychotic symptoms; delusion, hallucination, fear from family members with normal examination and investigations. In addition; she responded well to antipsychotic medications. The post-partum psychosis in the studied case caused and precipitated by prolonged hospital stay, emotional and physical stress. ${ }^{1}$ Previously, authors concluded that the post-partum sleep deprivation may lead to development of mental and behavior disorders and subsequent PPS. ${ }^{2}$ The PPS of the studied case can be caused by the stress of 2 consecutive cesarean sections, increased corticosteroid level during the stress of surgeries ${ }^{3}$ and decreased immune response due to dengue fever. ${ }^{4}$

Previous studies demonstrated definite correlation between stress of surgeries, cortisol level, fever and PPS..$^{2-4}$ This case report represents a case of cesarean section for women with dengue fever and thrombocytopenia complicated by post-partum psychosis to highlights the importance of multidisciplinary team approach in management of such cases.

\section{Acknowledgments}

None. 


\section{Conflicts of interest}

The author declares there are no conflicts of interest.

\section{References}

1. Davies W. Understanding the pathophysiology of postpartum psychosis: Challenges and new approaches. World J Psychiatry. 2017;7(2):77-88.

2. Pirjo Kettunen, Eeva Koistinen, Jukka Hintikka. The Connections of Pregnancy, Delivery, and Infant-Related Risk Factors and Negative Life
Events on Postpartum Depression and Their Role in First and Recurrent Depression. Depress Res Treat. 2016:2514317.

3. Bergink V, Burgerhout $\mathrm{KM}$, Weigelt $\mathrm{K}$, et al. Immune system dysregulation in first-onset postpartum psychosis. Biol Psychiatry. 2013;73(10):1000-1007.

4. Brummelte S, Galea LA. Post-partum depression: Etiology, treatment and consequences for maternal care. Horm Behav. 2016;77:153-166. 